\title{
ERRATUM
}

\section{Yoshiro Ishimaru}

\section{Molecular mechanisms of taste transduction in vertebrates}

\section{Erratum to: Odontology (2009) 97:1-7 \\ DOI 10.1007/s10266-008-0095-y}

Some of the vertical rules in Fig. 2 (immediately below the headings "sweet," "umami," etc.) were inadvertently deleted during the editorial production process.

The figure is correctly shown here.

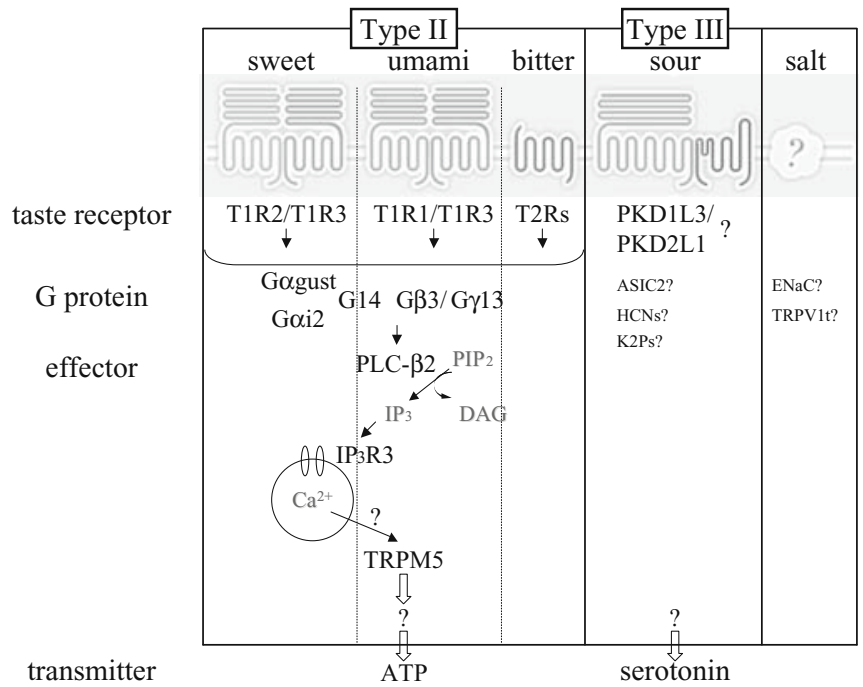

Fig. 2

The online version of the original article can be found under doi: 10.1007/s10266-008-0095-y.

Y. Ishimaru $(\square)$

Department of Applied Biological Chemistry, Graduate School of

Agricultural and Life Sciences, The University of Tokyo,

1-1-1 Yayoi, Bunkyo-ku, Tokyo 113-8657, Japan

Tel. \& Fax +81-3-5841-1879

e-mail: ayishi@mail.ecc.u-tokyo.ac.jp 